\title{
Comorbidities among infertile women at NKST hospital Mkar-Gboko, North-Central Nigeria
}

\author{
Jonathan A. Karshima*, Victor C. Pam, Charles U. Anyaka, Iornum H. Shambe, \\ Maryam J. Ali, Bulus A. Dabu
}

Department of Obstetrics and Gynaecology, Jos University Teaching Hospital, Jos, Plateau state, Nigeria

Received: 15 August 2020

Accepted: 01 September 2020

\section{*Correspondence:}

Dr. Jonathan A. Karshima,

E-mail: jakarshima@ safemotherhoodpartners.org

Copyright: (C) the author(s), publisher and licensee Medip Academy. This is an open-access article distributed under the terms of the Creative Commons Attribution Non-Commercial License, which permits unrestricted non-commercial use, distribution, and reproduction in any medium, provided the original work is properly cited.

\begin{abstract}
Background: Infertility, a common, non-fatal ailment, is sometimes associated with substantial comorbidity that can add adverse outcomes during treatment or pregnancy and increase costs of care. This study aims to assess the magnitude and pattern of comorbidities in infertile Nigerian women.

Method: This descriptive retrospective study was undertaken at NKST Hospital Mkar-Gboko, Nigeria, from $1^{\text {st }}$ January 2005 to $31^{\text {st }}$ July 2013. Clinic records of patients who attended the gynaecological outreach clinic were retrieved and analyzed using descriptive statistics and test of associations with Microsoft Excel 2013. Jos University Teaching Hospital gave ethical clearance.

Results: 1,926 women seen during the study period, 1030 (53.5\%) presented for infertility care. 941 (91.4\%) women had complete records, among them, $476(50.5 \%)$ met the inclusion criteria, and their records were analyzed. The mean age of the women was $32.6 \pm 6.0$ years with a range of 20 to 53 years, see Table1. There were 52 comorbid conditions among the 476 women. The comorbidities included uterine myoma, previous appendectomy/pelvic surgeries, genital tract infections/retroviral disease, hypertension, obesity and diabetes, among others, see Table 4. Table 2 and 3 shows there is a significant statistical association between comorbidity type, age, parity, duration of infertility and symptoms complex between infertile women and comorbidities $(\mathrm{p}<0.05)$.

Conclusion: Comorbidities that can influence treatment and pregnancy outcomes are common among infertile women in central Nigeria. This finding strongly supports the routine assessment of women for comorbidities during infertility care for appropriate multidisciplinary management and counselling.
\end{abstract}

Keywords: Infertility, Comorbidities, Multidisciplinary care, Central Nigeria

\section{INTRODUCTION}

The prodigious statistics about population growth can inundate a weightier problem of population dynamics called "infertility" Infertility is a worldwide health concern, but mainly in the developing world, affecting 8 $15 \%$ of couples. ${ }^{1-4}$ It is puzzling, Africa that is overwhelmed with population statistics is also the most smashed with infertility problem and response because of cultural dynamics causing couples even in advanced age to desire childbearing. Infertility is also a multifactorial problem and therefore needs to be seen in the local context for the determinants, factors causing it and so the associated health challenges. It is a commonplace to see older females seeking infertility care and often presenting with other health issues. ${ }^{5}$ The literature is awash with women 60 years and older (the oldest 73 years) carrying pregnancies and delivering. ${ }^{6,7}$ Women with infertility could experience a myriad of comorbidities that might be gynaecological, medical, and surgical or the sequel of therapeutic interventions. The comorbidity defined as the presence of one or more additional conditions often cooccurring with the primary disease of interest describes the effect of all other conditions an individual patient might have other than the prime condition, and this can be physiological, psychological or economic. ${ }^{8}$ 
Though infertility by itself does not threaten physical health, it has a substantial impact on the physiological, psychological and social well-being of the woman. ${ }^{9,10}$ When also combined with comorbidity, can results in a varying mode of presentation and complication during treatment and in pregnancy. ${ }^{5,11}$ The increasing prevalence of medical disorders such as infectious diseases (genital and non-genital), diabetes, hypertension, and lifestyle diseases like obesity and addictions in the young are also known to contribute to the problem of infertility. ${ }^{1}$

Furthermore, infertility is not only a medical challenge but also takes a significant toll psychologically and financially on the patient. ${ }^{10}$ Besides, associated comorbidity may add adverse health outcomes, more complex clinical management, and increased health care costs for the infertility treatment and pregnancy that may follow. ${ }^{12}$ The compelling pressure of infertility, depending on the socio-economic and cultural setting from which the patient comes, may conceal the comorbidity including the manner of clinical presentation that often varies from one place to another. ${ }^{3,12,13}$ Additionally, the association of "overall" female infertility with later-life morbidity requires paradigm view in infertility causes and their management. ${ }^{14}$ The realisation of the effect of comorbidities on infertile women is thus critical for proper assessment of the patient towards identifying those at elevated risk from the infertility treatment or pregnancy. ${ }^{5}$ Hitherto, it appears there is ignorance about the influence of these coexisting medical conditions on the outcome of care for infertile patient. So also scanty at present, is information about the prevalence and effects of comorbidities on infertile women in our region. Therefore, this study aims to assess the magnitude of comorbidities and the clinical presentation in Nigerian infertile women, make appropriate recommendations for providing empathetic clinical and psychological care that can give value for the effort when the patient presents.

Aim of the study was to determine the magnitude and pattern of comorbidities and clinical presentation among infertile Nigerian women seen at a rural gynaecological outreach clinic.

\section{METHODS}

\section{Study type}

Study type was descriptive retrospective study.

\section{Study place and duration of study}

The study took place at NKST ('Nongu U Kristu U I Ser sha Tar') Hospital Mkar-Gboko, Benue State, northcentral, Nigeria. The facility is a 170-bed secondary level mission hospital, established in 1925. The study was over eight years, 1st January 2005 to 31st July 2013.

\section{Selection criteria}

The study subjects were selected from the women who registered at the outreach clinic to see the gynaecological team from Jos University Teaching Hospital, Jos. Most of the patients came by self-referral following the announcement by word of mouth in worship places. An outpatient register was kept on all patients who came to the clinic. The clinical impression of the patient's conditions/diagnosis was arrived at after history, physical examination and minimal investigation and recorded in the case notes. This study was based on the outpatient consultations in the gynaecological clinic; therefore, patients requiring gynaecological emergency attentions at the hospital were excluded. Comorbidity in this study was defined as a health condition other than the infertility, previous abdominal or pelvic surgery and a pre-existing medical ailment identified or declared by the patient during evaluation.

The inclusion criteria for the study included involuntary failure to conceive for over 12 months, patients with symptoms at presentation, previous abdominal/pelvic surgery and pre-existing medical illness. The exclusion criteria included: Infertility with no symptoms at presentation, no previous abdominal/pelvic surgery and no pre-existing medical ailment.

\section{Study procedure}

During the period, 1st January 2005 to 31st July 2013, all women who attended the gynaecology outreach clinic were identified from the outpatient register. Names of the patients and their hospital numbers were obtained. With this, case notes of the patients were retrieved from the health records department, and relevant data based on the inclusion criteria including age and parity were extracted and compiled, entered into Microsoft Excel spreadsheet and analysed.

\section{Ethical approval}

The management of NKST Hospital Mkar-Gboko and the research and ethic Committee of Jos University Teaching Hospital gave ethical approval for the study.

\section{Statistical analysis}

The data obtained were analysed by descriptive statistics and test of associations where appropriate using Microsoft Excel 2013 to get the frequencies, means and degree of significance. Tables 1-6 display the data.

\section{RESULTS}

Women with the complaint of inability to conceive were $1030(53.5 \%)$ out of 1,926 women seen during the period under review. The number of folders with complete information were 941, representing $92.0 \%$ of the infertile women. Of the 941 women, $476(50.5 \%)$ met the 
inclusion criteria, had at least one comorbidity, and formed the study subjects.

Among the women with comorbidities, 166 (38.8\%) had primary infertility while $310(61.2 \%)$ had secondary infertility. The age range was 20 to 53 years, with a mean age of $32.6 \pm 6.0$ years. Majority of the women $(n=296$, $62.2 \%$ ) were age 34 years or younger.

Most of the women $(n=417,87.6 \%)$ were of low parity, and the majority of them $(n=359,75.4 \%)$ had one or no child. Of the women, with previous deliveries $(n=241$, $50.6 \%), 17.8 \%$ had no living child

The mean duration of the infertility was 7.35 years \pm 5.06 years with a range of three months to 32 years. The peak period at presentation was four to eight years among
$56.3 \%$ of the women. Most of the women $(n=246$, $51.7 \%$ ) had their infertility for more than five years. (Table 1)

There were 52 comorbid conditions among the 476 infertile women studied. Of the 476 women, 224 (47.0\%), $77(16.0 \%)$, and $43(9.0 \%)$ of them had gynaecological, medical and surgically related morbidities respectively. In comparison, 132 (28.0\%) of the women had various combinations of morbidities beside infertility, (Table 2)

Table 2 and 3 show that there is a significant statistical association between comorbidity type, age, parity, duration of infertility and symptoms complex between infertile women and comorbidity types $(p<0.05)$ among the study subject.

Table 1: Distribution of the socio-demographic characteristic of women with comorbidity and infertility ( $n=476)$.

\begin{tabular}{|c|c|c|}
\hline Variable & Frequency & Percentage $(\%)$ \\
\hline \multicolumn{3}{|l|}{ Age (years) } \\
\hline$\leq 20$ & 4 & 1 \\
\hline $21-25$ & 53 & 11 \\
\hline $26-30$ & 149 & 31 \\
\hline $31-35$ & 123 & 26 \\
\hline $36-40$ & 107 & 22 \\
\hline $41-45$ & 29 & 6 \\
\hline $46-50$ & 9 & 2 \\
\hline$>50$ & 2 & 0 \\
\hline Total & 476 & 100 \\
\hline \multicolumn{3}{|l|}{ Parity $(n=476)$} \\
\hline 0 & 235 & 49 \\
\hline 1 & 124 & 26 \\
\hline 2 & 58 & 12 \\
\hline 3 & 26 & 5 \\
\hline 4 & 17 & 4 \\
\hline 5 & 11 & 2 \\
\hline$\geq 6$ & 5 & 1 \\
\hline Total & 476 & 100 \\
\hline \multicolumn{3}{|c|}{ Living children $(n=476)$} \\
\hline 0 & 278 & 58 \\
\hline 1 & 114 & 24 \\
\hline 2 & 41 & 9 \\
\hline 3 & 27 & 6 \\
\hline 4 & 9 & 2 \\
\hline 5 & 5 & 1 \\
\hline$\geq 6$ & 2 & 0 \\
\hline Total & 476 & 100 \\
\hline Child/mother & 1.8 & \\
\hline \multicolumn{3}{|c|}{ Duration of infertility (years) $(n=476)$} \\
\hline$<1$ & 18 & 4 \\
\hline 1,2 & 58 & 12 \\
\hline 3,4 & 100 & 21 \\
\hline 5,6 & 95 & 20 \\
\hline 7,8 & 73 & 15 \\
\hline 8,10 & 42 & 9 \\
\hline \multirow[t]{2}{*}{$>10$} & 90 & 19 \\
\hline & 476 & 100 \\
\hline
\end{tabular}

Continued. 


\begin{tabular}{|lll|}
\hline Variable & Frequency & Percentage $(\%)$ \\
\hline Range & 3 months-32 years \\
\hline Mean & 7.35 years \\
\hline Standard deviation & 5.1 \\
\hline
\end{tabular}

Table 2: Association between comorbidity type among infertile women $(n=476)$.

\begin{tabular}{|c|c|c|c|c|c|}
\hline Comorbidity type & Obsed & Exped & $\chi^{2}$ & Df & P value \\
\hline Gynecological conditions & 224 & 119 & & & \\
\hline Medical conditions & 77 & 119 & & & \\
\hline Surgical conditions & 43 & 119 & & & \\
\hline Multiple comorbidities & 132 & 119 & 153.43 & 3 & $<0.01$ \\
\hline
\end{tabular}

Table 3: Association between comorbidity type and age, parity, duration of infertility and symptoms among infertile women.

\begin{tabular}{|c|c|c|c|c|c|c|c|}
\hline & Gynaecological & Medical & Surgical & Multiple & $\mathbf{X}^{2}$ & Df & P value \\
\hline \multicolumn{8}{|c|}{ Women with comorbidities } \\
\hline \multicolumn{8}{|c|}{ Age $($ years $)(n=476)$} \\
\hline$\leq 34$ & 144 & 46 & 35 & 71 & 11.2 & 3 & 0.01 \\
\hline$\geq 35$ & 80 & 31 & 8 & 61 & & & \\
\hline \multicolumn{8}{|c|}{ Parity $(n=476)$} \\
\hline Para 0 & 109 & 39 & 25 & 62 & 35.07 & 3 & $<0.01$ \\
\hline Para $\geq 1$ & 115 & 38 & 18 & 70 & & & \\
\hline \multicolumn{8}{|c|}{ Duration of infertility (Years) $(n=476)$} \\
\hline$\leq 5$ & 97 & 45 & 22 & 66 & 44.97 & 3 & $<0.01$ \\
\hline$>5$ & 127 & 32 & 21 & 66 & & & \\
\hline \multicolumn{8}{|c|}{ Symptoms $(n=476)$} \\
\hline No & 57 & 25 & 12 & 21 & 299.18 & 3 & $<0.01$ \\
\hline Yes & 167 & 32 & 21 & 66 & & & \\
\hline \multicolumn{8}{|c|}{ Comparison of age, parity, \& duration of infertility with infertile women with comorbidities } \\
\hline \multicolumn{8}{|c|}{ Age $(n=941)$} \\
\hline Age (years) & Yes comorbidity & No comorbidity & $\mathbf{X}^{2}$ & Df & $P$ value & & \\
\hline$\leq 34$ & 296 & 354 & 21.41 & 1 & $<0.01$ & & \\
\hline$\geq 35$ & 180 & 111 & & & & & \\
\hline \multicolumn{8}{|l|}{ Parity } \\
\hline Para 0 & 235 & 267 & 6.12 & 1 & $<0.01$ & & \\
\hline Para $\geq 1$ & 241 & 198 & & & & & \\
\hline \multicolumn{8}{|c|}{ Duration of infertility (years) } \\
\hline$\leq 5$ & 230 & 221 & 0.06 & 1 & 0.81 & & \\
\hline$>5$ & 246 & 244 & & & & & \\
\hline
\end{tabular}

Table 4: Conditions amongst the infertile women that attended gynaecology outreach clinic $(\mathrm{n}=678)$.

\begin{tabular}{|llll|}
\hline S. no. & Condition & Number & Percentage (\%) \\
\hline $\mathbf{1}$ & Uterine fibroid & 147 & 22 \\
\hline $\mathbf{2}$ & Myomectomy & 59 & 9 \\
\hline $\mathbf{4}$ & Appendectomy & 47 & 7 \\
\hline $\mathbf{5}$ & Genital tract infection & 41 & 6 \\
\hline $\mathbf{6}$ & Retroviral diseases & 39 & 6 \\
\hline $\mathbf{7}$ & Ectopic pregnancies /Salpingectomy & 35 & 5 \\
\hline $\mathbf{8}$ & Depression & 33 & 5 \\
\hline $\mathbf{9}$ & Laparotomy & 32 & 5 \\
\hline $\mathbf{1 0}$ & Hypertensions & 31 & 5 \\
\hline $\mathbf{1 1}$ & Obesity & 25 & 4 \\
\hline $\mathbf{1 2}$ & Asherman's disease & 24 & 4 \\
\hline $\mathbf{1 3}$ & Tuboplasties & 23 & 3 \\
\hline
\end{tabular}




\begin{tabular}{|c|c|c|c|}
\hline S. no. & Condition & Number & Percentage $(\%)$ \\
\hline 14 & Ovarian cyst & 16 & 2 \\
\hline 15 & Candidiasis & 10 & 1 \\
\hline 16 & Diabetes mellitus & 9 & 1 \\
\hline 17 & Genital prolapse & 9 & 1 \\
\hline 18 & Malaria & 8 & 1 \\
\hline 19 & Anaemia & 7 & 1 \\
\hline 20 & CIN I-III/HSIL/Early CaCx & 6 & 1 \\
\hline 21 & Premature ovarian failure & 5 & 1 \\
\hline 22 & Cervical laceration & 4 & 1 \\
\hline 23 & Congenital Uterine anomaly & 4 & 1 \\
\hline 24 & Vulvo-vaginal warts & 3 & 0 \\
\hline 25 & Chronic pelvic pain & 3 & 0 \\
\hline 26 & Endometriosis & 3 & 0 \\
\hline 27 & Femoral hernia & 3 & 0 \\
\hline 28 & Urinary tract infections & 3 & 0 \\
\hline 29 & Gonadal dysgenesis & 2 & 0 \\
\hline 30 & Palpitation & 2 & 0 \\
\hline 31 & Filariasis & 2 & 0 \\
\hline 32 & Goitre & 2 & 0 \\
\hline 33 & 3o Perineal tear & 2 & 0 \\
\hline 34 & Ruptured uterus & 1 & 0 \\
\hline 35 & Enlarged kidneys & 1 & 0 \\
\hline 36 & Hearing impairment & 1 & 0 \\
\hline 37 & Helminthiasis & 1 & 0 \\
\hline 38 & Adenomyosis & 1 & 0 \\
\hline 39 & Stress incontinence & 1 & 0 \\
\hline 40 & Menorrhagia & 1 & 0 \\
\hline 41 & Lumbar gibbus & 1 & 0 \\
\hline 42 & Lipoma & 1 & 0 \\
\hline 43 & Breast lump & 1 & 0 \\
\hline 44 & Urge incontinence & 1 & 0 \\
\hline 45 & Previous right femor fracture with deformity & 1 & 0 \\
\hline 46 & Right hip pain & 1 & 0 \\
\hline 47 & Splenomegaly & 1 & 0 \\
\hline 48 & Suburethral cyst & 1 & 0 \\
\hline 49 & Cervical polyps & 1 & 0 \\
\hline 50 & Haemorrhoid & 1 & 0 \\
\hline 51 & Peritoneal schistosomiasis & 1 & 0 \\
\hline \multirow[t]{2}{*}{52} & Pulmonary tuberculosis & 1 & 0 \\
\hline & Total & 678 & 100 \\
\hline
\end{tabular}

Table 5: Distribution of presenting complaint(s) among infertile women with comorbidity that attended the gynaecology outreach clinic ( $n=1042)$.

\begin{tabular}{|llll|}
\hline S. no. & Presenting complaints & Frequency & Percentage (\%) \\
\hline $\mathbf{1}$ & Anal pain & 1 & 0 \\
\hline $\mathbf{2}$ & Back pain & 34 & 7 \\
\hline $\mathbf{3}$ & Bleeding at intercourse & 4 & 1 \\
\hline $\mathbf{4}$ & Body heat & 6 & 1 \\
\hline $\mathbf{5}$ & Body rash & 1 & 0 \\
\hline $\mathbf{6}$ & Breast discharge & 3 & 1 \\
\hline $\mathbf{7}$ & Cervical laceration & 1 & 0 \\
\hline $\mathbf{8}$ & Cough & 1 & 0 \\
\hline $\mathbf{9}$ & Excessive hair growth & 1 & 0 \\
\hline $\mathbf{1 0}$ & Fever & 1 & 0 \\
\hline $\mathbf{1 1}$ & Frequent urination & 1 & 0 \\
\hline
\end{tabular}




\begin{tabular}{|c|c|c|c|}
\hline S. no. & Presenting complaints & Frequency & Percentage (\%) \\
\hline 12 & Frequent urination at night & 2 & 0 \\
\hline 13 & Headache & 12 & 3 \\
\hline 14 & Heavy menstruation & 54 & 11 \\
\hline 15 & Infrequent coitus & 1 & 0 \\
\hline 16 & Irregular menstruation & 42 & 9 \\
\hline 17 & Low libido & 1 & 0 \\
\hline 18 & Lower abdominal pain & 182 & 38 \\
\hline 19 & Lower abdominal swelling & 67 & 14 \\
\hline 20 & Lump in breast & 1 & 0 \\
\hline 21 & Lump over right hip & 1 & 0 \\
\hline 22 & No menstruation & 63 & 13 \\
\hline 23 & Pain at intercourse & 5 & 1 \\
\hline 24 & Pain at urination & 1 & 0 \\
\hline 25 & Painful menstruation & 1 & 0 \\
\hline 26 & Palpitation & 4 & 1 \\
\hline 27 & Pelvic swelling & 1 & 0 \\
\hline 28 & Perineal pain & 1 & 0 \\
\hline 29 & Poor sleep & 3 & 1 \\
\hline 30 & Recurrent Child losses & 1 & 0 \\
\hline 31 & Recurrent pregnancy losses & 3 & 1 \\
\hline 32 & Scanty menstruation & 8 & 2 \\
\hline 33 & Second opinion & 1 & 0 \\
\hline 34 & Swelling in vagina & 7 & 1 \\
\hline 35 & Told has lesion on cervix & 1 & 0 \\
\hline 36 & Upper abdominal pain & 1 & 0 \\
\hline 37 & Vaginal discharge & 41 & 9 \\
\hline 38 & Vulval itch & 4 & 1 \\
\hline 39 & Wants to Conceive & 476 & 100 \\
\hline 40 & Weakness lower limb & 1 & 0 \\
\hline 41 & Weight gain & 2 & 0 \\
\hline \multicolumn{4}{|c|}{ Previous surgeries $(n=209)$} \\
\hline 1 & Myomectomy & 49 & 23 \\
\hline 2 & Appendicectomy & 47 & 22 \\
\hline 3 & Salpingectomy for Ectopic & 33 & 16 \\
\hline 4 & Laparotomy & 21 & 10 \\
\hline 5 & Caesarean Section & 19 & 9 \\
\hline 6 & Tuboplasty & 23 & 11 \\
\hline 7 & Ovarian cystectomy/Wedge resection & 11 & 5 \\
\hline 8 & Dilatation and curettage & 4 & 2 \\
\hline 9 & Previous Total abdominal hysterectomy & 1 & 0 \\
\hline \multirow[t]{2}{*}{10} & Ruptured uterus & 1 & 0 \\
\hline & Total & 209 & 100 \\
\hline
\end{tabular}

Table 6: Distribution of the main physical findings amongst the infertile women with comorbidity that attended gynaecology outreach clinic $(n=557)$.

\begin{tabular}{|llll|}
\hline S. no. & Physical findings & Frequency & Percentage (\%) \\
\hline $\mathbf{1}$ & Abdominal Scar & 194 & 35 \\
\hline $\mathbf{2}$ & Enlarged uterus & 159 & 29 \\
\hline $\mathbf{3}$ & Vaginal discharge & 40 & 7 \\
\hline $\mathbf{4}$ & Pelvic tenderness & 28 & 5 \\
\hline $\mathbf{5}$ & High blood pressure & 28 & 5 \\
\hline $\mathbf{6}$ & Galactorrhoea & 26 & 5 \\
\hline $\mathbf{7}$ & Obesity & 26 & 5 \\
\hline $\mathbf{8}$ & Hirsutism & 25 & 4 \\
\hline $\mathbf{9}$ & Genital prolapse & 7 & 1 \\
\hline
\end{tabular}

Continued. 


\begin{tabular}{|llll|}
\hline S. no. & Physical findings & Frequency & Percentage (\%) \\
\hline $\mathbf{1 0}$ & Pallor & 6 & 1 \\
\hline $\mathbf{1 1}$ & Acne & 4 & 1 \\
\hline $\mathbf{1 2}$ & Others & 14 & 3 \\
\hline & Total & 557 & 100 \\
\hline
\end{tabular}

Others include perineal laceration 2, no breast 1, inguinal swelling 2, cervical laceration 2, breast lump 1, genital warts 1, enlarged spleen 1, enlarged kidneys 1, rectal fistula 1, haemorrhoid 1, and urethral diverticulum 1.

The main complaints in the women beside inability to conceive were lower abdominal pain, abnormal menstruation, lower abdominal swelling, vaginal discharge and back pain. In the review of previous treatment, $165(34.7 \%)$ of the women had 209 abdominal surgeries, some of the women, $27.9 \%$ had more than one surgery. Majority of the women $391(82.1 \%)$ had notable findings on physical examination (Table 6).

\section{DISCUSSION}

The study showed that infertility is a common problem in central Nigeria and over half $(50.5 \%)$ of the women had at least a comorbidity significant enough to impact on the course of management of infertility and or the successful pregnancy that may follow. Gynaecological problems (uterine myoma, genital tract infections and tubal diseases), surgical problems (previous surgeries: myomectomies, tuboplasties, appendectomy and other laparotomies) and medical conditions (retroviral disease, depression, hypertension, obesity and diabetes) among others were the comorbidities identified in the study subject.

Secondary infertility was the commonest type of infertility in the study population. Secondary infertility has been a consistent finding in this country but at variance with the findings in Asia and North Africa' where primarily infertility is more prevalent. ${ }^{1,3,12,13,15-20,21}$ The high rate of secondary infertility against primary infertility suggests infection process from sexually transmittable infections, post-abortion and puerperal complications affecting the genital tract, especially the uterine tubes. ${ }^{15}$ The tubal factor is the most common cause of infertility in this country. $7,15,17,22$

The mean age of the women was $32.6 \pm 6$ years, with the majority of the women ages $\leq 34$ years. This mean age is far above the median national fecundity age of 21 years. ${ }^{18}$ The type of infertility and age distribution among the women that attended the outreach clinic represented a full spectrum of patients with infertility, from the early twenties to middle age and were similar to that observed by other studies. ${ }^{12,15,19,20}$ The women distribution shows the desire for fertility was expressed across all the age groups and reflects the cultural and social pressure childless women go through in the region. Though the majority of the women were 34 years and younger, there was no teenage girl among the patients with comorbidities. In a previous report from this centre and study from Bauchi, Gombe, and Sokoto in northern Nigeria reported the findings of women ages less than 20 years in $2 \%, 3.2 \%, 5.6 \%$ and $7.6 \%$ respectively. $3,4,8,12,23$ Furthermore, the average age of infertile women reported from most of the studies across the country is 25 to 35 years correlating with our finding. $8,16,17,22,23$ Likewise, when the oldest woman in our population was 53 years, the oldest at Calabar, Bauchi and Delta were 39, 42 and 45 years respectively, is suggesting advancement in the age women are opting for procreation in Nigeria. ${ }^{17,18,23}$ The mean age at presentation for uterine myoma reported

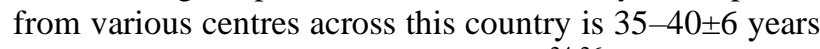
and least common by age 20-24..$^{24-26}$ Nnewi study reported that $76 \%$ and $30.1 \%$ of the women who presented with uterine myoma were nulliparous and infertile, respectively. ${ }^{26}$ In this study, age showed a statistically significant association with comorbidity in infertility as noted between patients $\leq 34$ years and those $>35$ years $(p<0.05)$. Considering that the prevalence of most non-communicable diseases rises with age, it is easy to understand the increasing prevalence of coexisting medical disorders in infertile patients over their lifespan and clinician need to take note of this trend. ${ }^{27}$ And as the older population increases, and with increasing availability of advanced infertility care that gives hope, more older childless Nigerian women will attend infertility clinics.

The wide range of parity (0-8 deliveries) among the women studied notwithstanding, the average fertility (1.0 \pm 1.4 deliveries) of the women was very low compared to the north-central zone total fertility rate of 5.0. ${ }^{18}$ The study found a statistically significant association between parity and comorbidity type in infertile women $(\mathrm{p}<0.05)$. This association supports the need for screening infertile women for comorbidity during evaluation.

Though some of the women (2\%) presented earlier (less than one year of not achieving pregnancy, some as early as three months of marriage) than the definition of infertility allows, a late presentation was common among the women. The mean period at presentation among the women with comorbidity was $7 \pm 5$ years. Most of these women $(52 \%)$ had infertility five years or over. ${ }^{7,8}$ the $2 \%$ women that reported earlier than this period echoes the societal pressure associated with a desire for procreation after marriage. ${ }^{13}$ The late presentation means the patients' are older by the time they present, as seen in this study. Although some got married at an early age, over half were in their late thirties and older, a time when their reproductive potentials could have started declining, risk of marital disharmony and comorbidities that can risk 
treatment and pregnancy set in as shown in this study. $.8,29,30$

The over half of the women that presented with infertility at Mkar had 52 comorbid conditions. The comorbidity types were statistically significant among the infertile women $(\mathrm{p}<0.05)$. The mean age at presentation with uterine myoma reported from centres across this country is $35-40 \pm 6$ years and least common by age $20-24.24,25,29$ Other centres reported similar findings of comorbid conditions among their study subjects., ${ }^{1,22,23}$ The associated comorbidities seen among the women could add adverse health outcomes, more complex clinical management, and increased health care costs for the treatment and pregnancies that may follow. Additionally, the association of "overall" female infertility with laterlife morbidity requires a paradigm view in infertility aetiologies and their management. As aforementioned, it is vital that infertile women, especially those aged thirty and older get proper assessment towards identifying those at elevated risk from the infertility treatment or pregnancy to provide appropriate empathetic clinical and psychological care that will give value for the effort. ${ }^{5}$

Comorbidity also adds to the dilemma of caring for infertile women in our environment. The delusive presenting complaints by the women can cause distraction in the clinical approach to management when there is comorbidity. We found that less than $50 \%$ of the women volunteered inability to conceive as their primary reason to visit the clinic. Non-presentation of failure to conceive as a primary complaint by women is a common feature in our clinics. ${ }^{15,23,30}$ Primary complaints like headache, sleeplessness, backache etc. have been reported in many studies across this country depending on cultural inclinations. . $^{2,5,12,19}$ These delusive presentations of infertility in the face of comorbidity have the potential of misdirecting the weary clinician towards wrong diagnosis and inappropriate intervention. For examples, 34.7\% of the women had abdominal surgeries with myomectomy, appendectomy, ectopic pregnancy and unspecified laparotomy as the primary $(68 \%)$ reasons for the surgeries. Some of the women $(19.6 \%)$ had the surgeries more than once. Most of these surgeries might be to resolve the women complain of abdominal pain. Certainly, these interventions where spuriously done can pose a significant risk to the woman who has infertility.

It may also be on the same premise that some women are treated severally for 'chronic' pelvic inflammatory diseases or psychiatric disorders, thereby compounding the woman's concern for failure to conceive. ${ }^{3,12,19,30}$ Infertility, by itself, does not threaten physical health. However, when combined with comorbidity can result in a varying mode of presentation and complication during treatment and in pregnancy, consequently, with a substantial impact on the physiological, psychological and social well-being of the woman as seen in this study. ${ }^{19,29}$ It is the realisation of the effect of comorbidities on infertile women that proper assessment of the patient is critical and strongly advocated to identify those at elevated risk from the infertility treatment or pregnancy. 5

\section{Limitation of the study}

This was a retrospective study conducted in a rural secondary care centre during outreach visits. Being a retrospective study, we were just able to gather information from clinical history, physical finding and some basic investigations at the point of contact to arrive at the diagnosis for the care of the women. Therefore, there could be a possibility of missing out some characteristics that may make some patients distinct compared to other infertile women. Future populationbased studies are required to validate some of the findings from this study.

\section{CONCLUSION}

Infertility is associated with significant comorbidity burden among women in this study population. With over $50 \%$ of the women in our study with additional health problem besides infertility calls for all infertile women (particularly those age above 30 years) attending our clinics also to get screened for other health challenges towards identifying those at elevated risk from the infertility treatment or pregnancy.

\section{ACKNOWLEDGMENTS}

The authors acknowledge with gratitude the cooperation and support of the leadership and staff of the NKST Hospital Mkar-Gboko for the permission to use their facility for the medical outreach. We also appreciate the staff of the Safe motherhood partners for the record retrievals and our colleagues from various institutions, particularly consultants and resident doctors of the department of obstetrics and gynaecology, JUTH, who covered our duties while in the field for the outreach work. The support is very much valued.

\section{Funding: No funding sources \\ Conflict of interest: None declared \\ Ethical approval: The study was approved by the Institutional Ethics Committee}

\section{REFERENCES}

1. Deshpande PS, Gupta AS. Causes and prevalence of factors causing infertility in a public health fa-cility. J Hum Reprod Sci. 2019;12(4):287-93.

2. Otubu JAM. Infertility. In: Agboola A, ed. Textbook of Obstetrics and Gynaecology for Medical Students. 2nd ed. Ibadan, Heinemann Educational Books, Nigeria, Plc; 2006: 128-138.

3. Audu MA, Massa AA, Bukar M. Clinical Presentation of Infertility in Gombe, North-Eastern Nigeria. Trop J Obstet Gynaecol. 2003;20(2):93-6.

4. Puscheck, EE, Woodad, TZ. Infertility: Practice Essential e-Medicine Specialties; Obstetrics and Gynaecology 2015. Available at http://emedicine. 
medscape.com/article/274143. Accessed on 12 July 2020.

5. Ethics Committee, ASRM PAGES. Provision of fertility services for women at increased risk of complications during fertility treatment or pregnancy: an Ethics Committee opinion; Fertility and Sterility. Available at http: www.fertstert.org/article/S0015-0282. Accessed on 1 August 2020.

6. Karshima, JA, Pam VC, Shambe IH, Anyaka CU, Reich MI. Clinical Presentation of Infertility in Mkar-Gboko, North Central Nigeria. Int J Med Hea Sci res. 2016;3(2):24-30.

7. A 74-year-old woman in India may have given birth to twins, making her the world's oldest mother. Available at https://www.insider.com/74-year-oldwoman-give-birth-to-twins-with-ivf-2019-9.

Accessed on 17 September 2019.

8. Wikipedia contributors. 2020, July 26. Comorbidity. In Wikipedia, The Free Encyclopaedia. Available at https://en.wikipedia.org/w/index.php?title=Comorbid ity\&oldid=969674576. Accessed on 7 August 2020.

9. Forti G, Krausz C. Clinical review 100: Evaluation and treatment of the infertile couple. J Clin Endocrinol Metab. 1998;83(12):4177-88.

10. Patel A, Sharma PSVN, Kumar P, Binu VS. Sociocultural Determinants of Infertility Stress in Patients Undergoing Fertility Treatments. J Hum Reprod Sci. 2018;11(2):172-9.

11. Baby A, Varghese AA, Jose C, Kandasamy K, Sundaram SR. A Prospective Evaluation Of Causes and Treatment of Infertility in A Tertiary Care Hospital, Erode. Asian J Pharm Clin Res. 2018;11(2):149-53.

12. Panti AA, Sununu YT. The Profile of Infertility in a Teaching Hospital in Northwest Nigeria. Sahel Medical J. 2014;17(1):7-11.

13. Mustapha A, Gbadebo AA, Jika YA, AJ Randawa, Biliaminu L. Psychosocial morbidity in women attending an infertility clinic in North-western Nigeria: 'It's the worst misfortune of a woman'. J gynaecol Obste. 2015;3(1):6-12.

14. Tarín JJ, García-Pérez MA, Hamatani T, Cano A. Infertility aetiologies are genetically and clinically linked with other diseases in single meta-diseases. Reprod Biol Endocrinol. 2015;13:(31):2-11.

15. Karshima JA, Daru PH, Ekedigwe JE. Hysterosalpingographic (HSG) evaluation of 998 consecutive infertile women in Jos, Nigeria. Int $\mathbf{J}$ Gynaecol Obstet. 2010; 108(3):255-7.

16. Sule JO, Erigbali P, Eruom L. Prevalence of Infertility in Women in a southwestern Nigerian Community. Afr J Biomed res. 2008;11:225-7.

17. Odunvbun WO, Oziga DV, Oyeye LO, Ojeogwu CL. Pattern of infertility among infertile couple in a secondary health facility in Delta State, South south Nigeria. Trop J Obstet Gynaecol. 2018;35:244-8.

18. National Population Commission (NPC) Nigeria and ICF. 2019. Nigeria Demographic and Health Survey 2018. Abuja, Nigeria, and Rockville, Maryland, USA: NPC and ICF. https://dhsprogram.com/ publications/publication-fr359-dhs-final-reports.cfm. Accessed on 5 August 2020.

19. Obuna JA, Ndukwe EO, Ugboma HAA, Ejikeme BN, Ugboma EW. Clinical Presentation of Infertility in an Outpatient Clinic of a Resource Poor Setting, South-East Nigeria. Int $\mathbf{J}$ trop dis health. 2012;2(2):123-31.

20. Adeyemi AS, Adekanle DA, Afolabi AF. Pattern of gynaecological consultation at Ladoke Akintola University of Technology Teaching Hospital. NIG. J Clin Pract. 2009;12(1):47-50.

21. Benbella A, Aboulmakarim S, Hardizi H, Zaidouni A, Bezad R. Infertility in the Moroccan population: an etiological study in the reproductive health centre in Rabat. Pan Afr Med J. 2018;30:204.

22. Ekwere, PD, Achibong, EI, Bassey, EE, Ekabura, JE, Ekannem, EI, Feyi-Waboso, P. Infertility among Nigerian Couples as Seen in Calabar. Port Harcourt Med J. 2007;2:35-40.

23. Dattijo LM, Andreadis N, Aminu BM, Umar NI, Black KI. Prevalence and Clinical Pattern of Infertility in Bauchi, Northern Nigeria. Trop J Obstet Gynaecol. 2016;33(1)76-85.

24. Daru PH, Pam IC, Garba IO, Ekwempu CC, Kigbu JH, Mutihir JT. Indications for abdominal hysterectomy at the Jos University Teaching Hospital. Highland med res J. 2008;6:1-2.

25. Omole-Ohonsi A and Belga F. Surgical Management of Uterine Fibroids at Aminu Kano Teaching Hospital. Obst Gynecol Int. 2012;1-6.

26. Ezeama CO, Ikechebelu JI, Obiechina NJ, Ezeama NN. Clinical presentation of uterine fibroids in Nnewi, Nigeria: A 5-year review. Ann Med Health Sci Res. 2012;2:114-8.

27. Chou WC, Chang $\mathrm{PH}, \mathrm{Lu} \mathrm{CH}$, et al. Effect of Comorbidity on Postoperative Survival Outcomes in Patients with Solid Cancers: A 6-Year Multicentre Study in Taiwan. J Cancer. 2016;7(7):854-61.

28. Chandra A, Copen CE, Stephen EH. Infertility and impaired fecundity in the United States, 1982-2010: data from the National Survey of Family Growth. Natl Health Stat Report. 2013;14;(67):1-18.

29. Feldman-Savelsberg P. Plundered kitchens and empty wombs: fear of infertility in the Cameroonian grass field. Soc Sci Med. 1994;39:463-74.

30. Karshima JA, Pam VC, Atim T, Abata PP, Reich MI. Indications for Gynaecological Consultation by Women at a Rural Outreach Centre in North-Central Nigeria. Int J trop dis Hea. 2014;4(6):696-712.

Cite this article as: Karshima JA, Pam VC, Anyaka CU, Shambe IH, Ali MJ, Dabu BA. Comorbidities among infertile women at NKST hospital MkarGboko, North-Central Nigeria. Int J Reprod Contracept Obstet Gynecol 2020;9:3922-30. 